\title{
Analytical Solution of a Circular Opening considering Nonuniform Pressure and Its Engineering Application
}

\author{
Peng Wu, ${ }^{1}$ Yanlong Chen $\mathbb{D D}^{1}{ }^{1}$ Liang Chen, ${ }^{2,3}$ Xianbiao Mao, ${ }^{1}$ and Wei Zhang $\mathbb{D}^{2}$ \\ ${ }^{1}$ State Key Laboratory for Geomechanics and Deep Underground Engineering, China University of Mining \& Technology, \\ Xuzhou 221116, China \\ ${ }^{2}$ State Key Laboratory of Coal Resources and Safe Mining, China University of Mining \& Technology, Xuzhou 221116, China \\ ${ }^{3}$ School of Mines, China University of Mining \& Technology, Xuzhou 221116, China \\ Correspondence should be addressed to Yanlong Chen; chenyanlong@cumt.edu.cn
}

Received 1 September 2020; Revised 7 November 2020; Accepted 29 November 2020; Published 24 December 2020

Academic Editor: Zhushan Shao

Copyright (C) 2020 Peng Wu et al. This is an open access article distributed under the Creative Commons Attribution License, which permits unrestricted use, distribution, and reproduction in any medium, provided the original work is properly cited.

\begin{abstract}
Based on the Mohr-Coulomb criterion, a new analytical solution of a circular opening under nonuniform pressure was presented, which considered rock dilatancy effect and elastic-brittle-plastic failure characteristics. In the plastic zone, the attenuation of Young's modulus was considered using a radius-dependent model (RDM), and solution of the radius and radial displacement of plastic zone was obtained. The results show that many factors have important impact on the response of the surrounding rock, including lateral pressure coefficient, dilation coefficient, buried depth, and Young's modulus attenuation. Under nonuniform pressure condition, the distribution of plastic zone and deformation around the opening show obvious nonuniform characteristic: with the increasing of lateral pressure coefficient, the range of plastic zone and deformation decrease gradually at side, while they increase at roof and floor, and the location of the maximum value of support and surrounding rock response curve transfers from side to roof. Based on the analytical results and engineering practice, an optimization method of support design was proposed for the circular opening under nonuniform pressure.
\end{abstract}

\section{Introduction}

It is important to predict the distribution of stress and deformation accurately for a deep circular opening, which is the basis for evaluating the stability of surrounding rock and reliability of support design in deep mining and other underground engineering. Many efforts have been paid on this topic, based on the linear Mohr-Coulomb (M-C) criterion or nonlinear Hoek-Brown (H-B) criterion, considering ideal elastic-plastic model (EPM), elastic-brittle-plastic model (EBM), or strain-softening model [1-11]. In the previous researches, the stress was usually assumed to be uniform, and the influence of lateral pressure coefficient on the stressstate distribution of surrounding rock was ignored. However, many engineering practices indicate that the gravity stress of the overlying strata and the tectonic stress usually lead to the nonuniform stress distribution in the surrounding rock [12-16]. Some theoretical analysis and numerical simulation results indicate that the lateral pressure coefficient has a remarkable influence on the stress state of surrounding rock [17-19]. Therefore, the research results without considering the effect of lateral pressure coefficient are inconsistent with the engineering conditions. In the present research, a mechanical model for circular opening with nonuniform confining pressure is first proposed. Then, the impacts of the lateral pressure coefficient on the distribution of plastic zone in the surrounding rock and the response curve of the support system were analyzed.

When the surrounding rock undergoes plastic deformation, the mechanical properties of the rock mass may change due to rock damage, such as the attenuations of internal friction angle, cohesion, Young's modulus, and Poisson's ratio. As for Young's modulus, at present, there are two methods to define the attenuation process for the postpeak rock. In the first method, Young's modulus of the postpeak rock is determined by confining pressure and minimum 
principal stress, which is named the pressure-dependent Young's modulus model (PDM) [20-22]. In the other method, Young's modulus decreases with some function relationship along the radius direction of the surrounding rock, which is called the radius-dependent Young's modulus model (RDM) [23-26]. The RDM is regarded as the extension of PDM. It is thought that the close relationship between Young's modulus attenuation and rock fracture can explain efficiently the large deformation problems of surrounding rock in the deep underground engineering [27]. In the present work, the RDM is adopted to account for the effect of Young's modulus attenuation. In addition, some scholars regard the surrounding rock as viscoelastic model [28-33] and deduce a series of simplified formulas for lining pressure and tunnel convergence, which provides an effective method for predicting the time-varying displacement and stress field of surrounding rock of deepburied circular tunnel. Wu and Shao [34-36] proposed using flexible layer to deal with large deformation of tunnel in viscoelastic rock mass. Theory and engineering practice shows that flexible layer has a good absorption effect on rock rheological deformation.

Based on the proposed mechanical model, the closedform solutions of stress, deformation, and radius of plastic zone of the surrounding rock in circle opening with nonuniform confining pressure was obtained. The influence of the lateral pressure coefficient, dilation coefficient, and Young' modulus attenuation on the response of the surrounding rock was studied. Then, according to the engineering practices in different geological conditions, a support design method was proposed considering nonuniform stress state.

\section{Analytical Solution of the Circular Opening}

\subsection{Fundamental Assumptions}

2.1.1. Yield Criterion. As shown in Figure 1, a circular opening with a radius of $r_{0}$ is excavated in the uniform, isotropic, and continuous rock media. The internal support pressure $\left(p_{\text {in }}\right)$ acts on the location of $r_{0}$, and the vertical stress $\left(\sigma_{0}\right)$ and the lateral pressure $\left(\lambda \sigma_{0}\right)$ act at the outer boundaries, where $\lambda$ is the lateral pressure coefficient. The stress of surrounding rock redistributes after excavation. When the stress reaches the yield strength of the rock mass, plastic deformation will occur, and the radius of plastic zone is represented by $r_{j}$ in Figure 1.

In the paper, the linear M-C yield criterion was adopted as yield condition of surrounding rock, and it is expressed as $[5,8,23]$

$$
\sigma_{1}=\xi \sigma_{3}+Y
$$

where $\sigma_{1}$ and $\sigma_{3}$ are the maximum stress and minimum principal stress, respectively, $Y=2 c \cos \varphi /(1-\sin \varphi)$, $\xi=(1+\sin \varphi) /(1-\sin \varphi)$, and $c$ and $\varphi$ are the cohesion and internal friction angle of the rock, respectively.

For the plane strain problem of the circular tunnel, the hoop stress $\left(\sigma_{\theta}\right)$ and radial stress $\left(\sigma_{r}\right)$ are the maximum and minimum principal stress, respectively [17], which means that $\sigma_{1}=\sigma_{\theta}$ and $\sigma_{3}=\sigma_{r}$. Then, equation (1) could be represented as

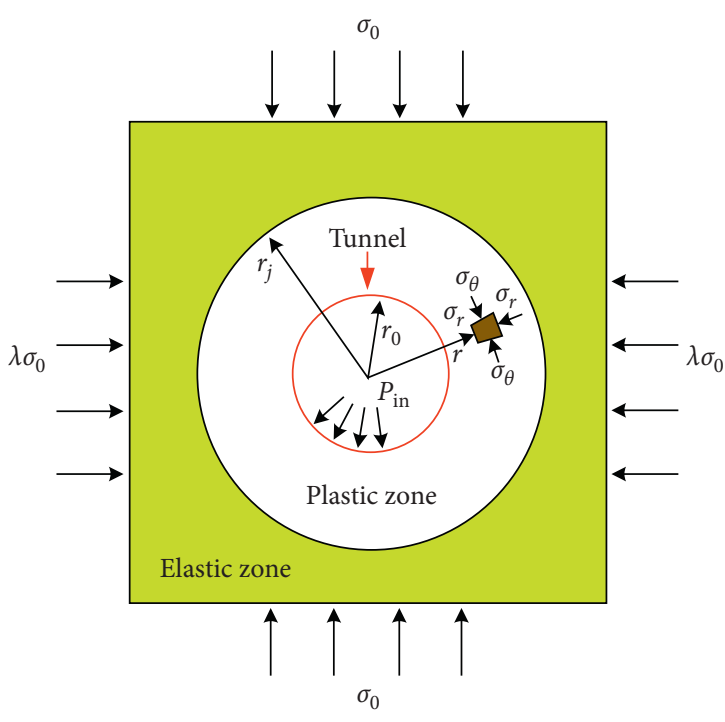

Figure 1: Mechanical model of a deep circular opening.

$$
\sigma_{\theta}=\xi \sigma_{r}+Y
$$

Considering the elastic-brittle characteristic of rock mass, there is a stress drop after the peak strength $[5,9,10]$, after which the rock mass undergoes postpeak-flow state. In the postpeak region, the residual rock parameters are used (residual cohesion $c_{r}$, residual internal frictional angle $\varphi_{r}$, and residual Poisson's ratio $v_{r}$ ).

2.1.2. Attenuation of Young's Modulus. The mechanical behavior of surrounding rock is closely related with its damage in the plastic zone. The higher damage usually leads to larger deformation ability. Then, the attenuation of Young's modulus should be considered in the plastic zone. In general, the damage of the rock mass can be expressed by the attenuation of Young's Modulus. Based on previous researches [23, 24], a radius-dependent Young's modulus attenuation model (RDM) with a power function is adopted here as follows:

$$
E(r)=E_{r}\left(\frac{r}{r_{0}}\right)^{\alpha},
$$

where $E$ and $E_{r}$ are the initial and residual Young's modulus, respectively, $\alpha=\log \left(E / E_{r}\right) / \log \left(r_{j} / r_{0}\right)$, if $\alpha=0$ and $E=E_{r}$.

Equation (3) shows that the attenuation of Young's modulus is not only related to the initial and residual Young's modulus but also closely related to the radius of the plastic zone. Compared with the solution presented by Zhang and Ewy [23, 24], the solution of this paper is obtained under nonuniform pressure, and the influence of lateral pressure coefficient on the surrounding rock state is considered. Therefore, the radius of plastic zone in different positions around the surrounding rock varies, and the attenuation degree of Young's modulus is also nonuniform around the opening.

According to equation (3), at the boundaries of the plastic zone, Young's modulus should be 


$$
\begin{aligned}
& E(r)_{r=r_{j}}=E, \\
& E(r)_{r=r_{0}}=E_{r} .
\end{aligned}
$$

2.2. Fundamental Equations. The equilibrium equation in the elastic zone and the plastic zone is

$$
\frac{\mathrm{d} \sigma_{r}}{\mathrm{~d} r}+\frac{\left(\sigma_{r}-\sigma_{\theta}\right)}{r}=0 .
$$

The strain-displacement relationship is

$$
\begin{aligned}
& \varepsilon_{r}=\frac{\mathrm{d} u}{\mathrm{~d} r}, \\
& \varepsilon_{\theta}=\frac{u}{r} .
\end{aligned}
$$

For the plane strain problem, the constitute equation, i.e., Hooke's law, is

$$
\left\{\begin{array}{l}
\varepsilon_{r}=\frac{1+\nu}{E}\left[(1-\nu)\left(\sigma_{r}-\sigma_{0}\right)-v\left(\sigma_{\theta}-\sigma_{0}\right)\right], \\
\varepsilon_{\theta}=\frac{1+\nu}{E}\left[(1-\nu)\left(\sigma_{\theta}-\sigma_{0}\right)-v\left(\sigma_{r}-\sigma_{0}\right)\right] .
\end{array}\right.
$$

where $v$ is Poisson's ratio.

2.3. Solution of Stress and Deformation in Elastic Zone. To solve the problems of a circular opening under nonuniform stress field, the stress conditions at boundaries are divided into two parts [37], as shown in Figure 2. The first part (Figure 2(a)) is uniform compressive stress field with a value of $\sigma_{0}^{u}=(1+\lambda) \sigma_{0} / 2$; and the second one (Figure $\left.2(\mathrm{~b})\right)$ is the stress field with horizontal tensile stress and vertical compressive stress, the value is $\sigma_{0}^{n}=(1-\lambda) \sigma_{0} / 2$. In addition, $R$ represents an infinite position that the stress state is equal to in situ stress.

2.3.1. Solution of Uniform Compressive Stress Field. Computational mechanics model of uniform compressive stress field is presented in Figure 2(a). Based on elastic theory, the stress of the elastic zone under uniform pressure is obtained on the consideration of stress boundary conditions $\sigma_{r e}=p_{y}$ on elastic-plastic interface $r=r_{j}$ (where $p_{y}$ is the radial stress in elastic-plastic interface):

$$
\left\{\begin{array}{l}
\sigma_{r e}^{U}=\frac{(1+\lambda) \sigma_{0}}{2}\left(1-\frac{r_{j}^{2}}{r^{2}}\right)+p_{y} \frac{r_{j}^{2}}{r^{2}}, \\
\sigma_{\theta e}^{U}=\frac{(1+\lambda) \sigma_{0}}{2}\left(1+\frac{r_{j}^{2}}{r^{2}}\right)-p_{y} \frac{r_{j}^{2}}{r^{2}} .
\end{array}\right.
$$

where the subscript notation $e$ represents the elastic zone.

2.3.2. Solution of Stress Field with Horizontal Tensile Stress and Vertical Compressive Stress. As shown in Figure 2(b), for a point in the surrounding rock with the position of $r=R$, the stress at the point is original rock stress, and the stress boundary conditions are $\sigma_{x}=-(1-\lambda) \sigma_{0} / 2, \quad \sigma_{y}=$ $(1-\lambda) \sigma_{0} / 2$, and $\tau_{x y}=0$. So the stress expression in polar the coordinate is as follows:

$$
\left\{\begin{array}{l}
\sigma_{r}=-\frac{1}{2}(1-\lambda) \sigma_{0} \cos 2 \theta \\
\tau_{r \theta}=\frac{1}{2}(1-\lambda) \sigma_{0} \sin 2 \theta
\end{array}\right.
$$

Equation (9) gives the outer boundary conditions at the position of $r=R$. And the internal boundary condition under $r=r_{j}$ is shown as follows:

$$
\left\{\begin{array}{l}
\left(\sigma_{r}\right)_{r=r_{j}}=0 \\
\left(\tau_{r \theta}\right)_{r=r_{j}}=0
\end{array}\right.
$$

From equations (9) and (10), using the semi-retro-solution method [37], the stress function in the elastic zone is

$$
F=f(r) \cos 2 \theta \text {. }
$$

Substituting equation (11) into the compatible equation in the polar coordinate system, i.e., $\left(\left(\partial^{2} / \partial r^{2}\right)+\right.$ $\left.(1 / r)+(\partial / \partial r)+\left(1 / r^{2}\right)+\left(\partial^{2} / \partial \theta^{2}\right)\right) F=0$, the expression of stress function is determined as follows:

$$
F=\left(A_{1} r^{4}+A_{2} r^{2}+A_{3}+\frac{A_{4}}{r^{2}}\right) \cos 2 \theta,
$$

where $A_{1}, A_{2}, A_{3}$, and $A_{4}$ are all constants.

The stress component is solved by equation (12), combined with the boundary condition expressions (9) and (10). The result is as follows:

$$
\left\{\begin{array}{l}
\sigma_{r e}^{N}=\frac{1}{r} \frac{\partial F}{\partial r}+\frac{1}{r^{2}} \frac{\partial^{2} F}{\partial \theta^{2}}=-\frac{(1-\lambda) \sigma_{0}}{2}\left(1-4 \frac{r_{j}^{2}}{r^{2}}+3 \frac{r_{j}^{4}}{r^{4}}\right) \cos 2 \theta \\
\sigma_{\theta e}^{N}=\frac{\partial^{2} F}{\partial r^{2}}=\frac{(1-\lambda) \sigma_{0}}{2}\left(1+3 \frac{r_{j}^{4}}{r^{4}}\right) \cos 2 \theta .
\end{array}\right.
$$

By superposing the two stress fields mentioned above, the stress equation of elastic zone of a circular opening under nonuniform stress field can be obtained: 


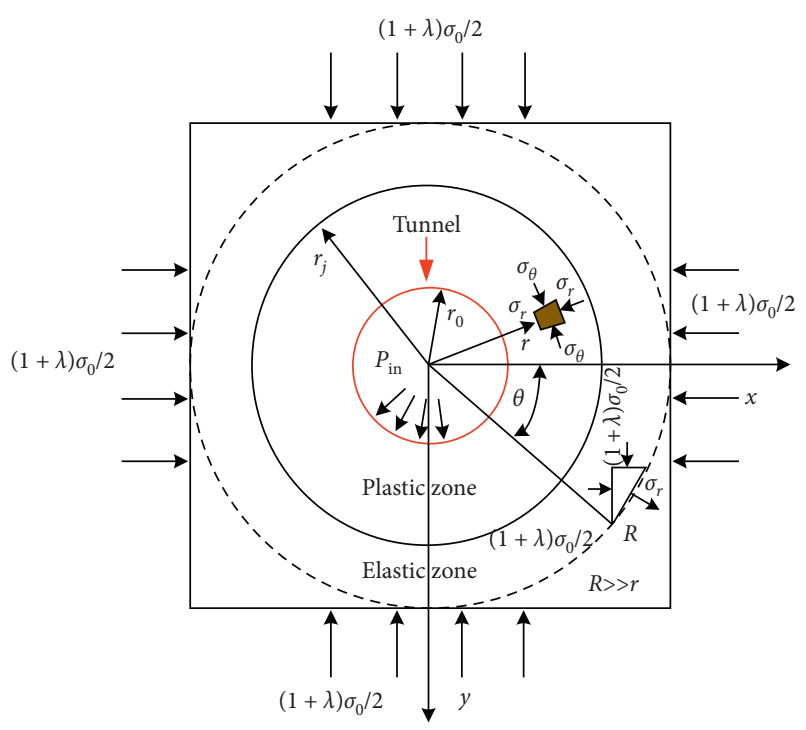

(a)

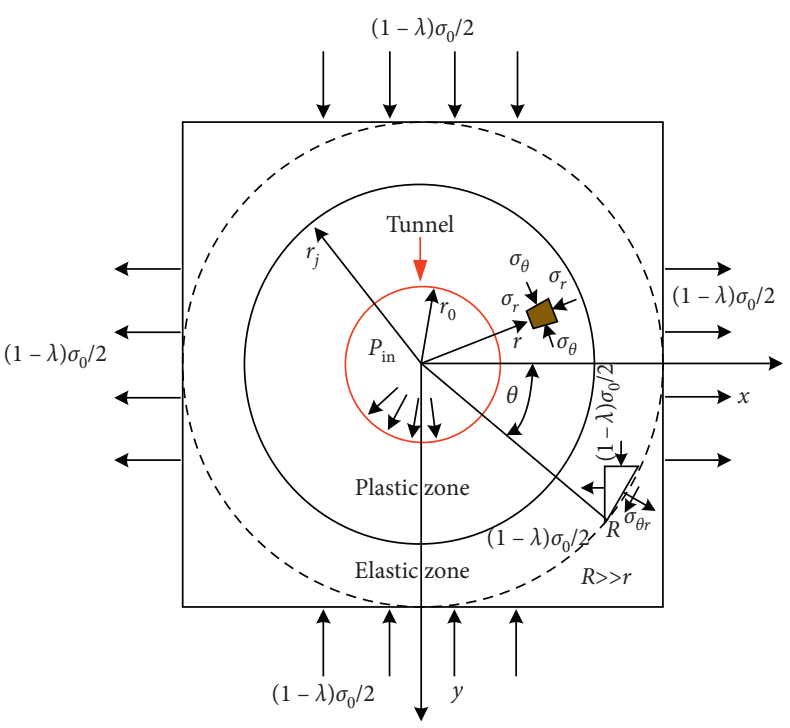

(b)

Figure 2: Equivalent mechanical model of a deep circular opening. (a) Uniform compressive stress field. (b) The stress field with horizontal tensile stress and vertical compressive stress.

$$
\left\{\begin{array}{l}
\sigma_{r e}=\sigma_{r e}^{U}+\sigma_{r e}^{N}=\frac{(1+\lambda) \sigma_{0}}{2}\left(1-\frac{r_{j}^{2}}{r^{2}}\right)+p_{y} \frac{r_{j}^{2}}{r^{2}}-\frac{(1-\lambda) \sigma_{0}}{2}\left(1-4 \frac{r_{j}^{2}}{r^{2}}+3 \frac{r_{j}^{4}}{r^{4}}\right) \cos 2 \theta, \\
\sigma_{\theta e}=\sigma_{\theta e}^{U}+\sigma_{\theta e}^{N}=\frac{(1+\lambda) \sigma_{0}}{2}\left(1+\frac{r_{j}^{2}}{r^{2}}\right)-p_{y} \frac{r_{j}^{2}}{r^{2}}+\frac{(1-\lambda) \sigma_{0}}{2}\left(1+3 \frac{r_{j}^{4}}{r^{4}}\right) \cos 2 \theta .
\end{array}\right.
$$

When $\lambda=1$, equation (14a) will be transferred into the stress expression in the elastic zone under uniform pressure, as given in equation (14b), which is consistent with the results of other researchers [5]:

$$
\left\{\begin{array}{l}
\sigma_{r e}=\sigma_{0}-\left(\sigma_{0}-p_{y}\right) \frac{r_{j}^{2}}{r^{2}}, \\
\sigma_{\theta e}=\sigma_{0}+\left(\sigma_{0}-p_{y}\right) \frac{r_{j}^{2}}{r^{2}} .
\end{array}\right.
$$

Substituting equations (7) and (14a) into equation (6), the displacement of the elastic zone on consideration of stress instantaneous release is

$$
u_{r e}=\frac{(1+v) r}{E}\left(\alpha_{1}+\alpha_{2} \frac{r_{j}^{2}}{r^{2}}+\alpha_{3} \frac{r_{j}^{4}}{r^{4}}\right),
$$

where $\quad \alpha_{1}=(1-\lambda) \nu \sigma_{0}, \quad \alpha_{3}=\left(3(1-\lambda) \sigma_{0} / 2\right), \quad$ and $\alpha_{2}=\left((1+\lambda) \sigma_{0} / 2\right)-2(1-\lambda) \nu \sigma_{0} \cos 2 \theta-p_{y}$.

When $r=r_{j}$, the radial displacement at elastoplastic interface is

$$
u_{r_{j}}=\frac{(1+\nu) r_{j}}{E}\left(\alpha_{1}+\alpha_{2}+\alpha_{3}\right)
$$

As the surrounding rock is at the state of critical yield stress at elastoplastic interface, its circumferential and radial stresses both satisfy the yield criterion at peak point. Then, substituting equation (14a) into equation (2), the radial contact stress of elastoplastic zone with $\mathrm{M}-\mathrm{C}$ criterion is

$$
p_{y_{1}}=\frac{1}{1+\xi}\left[(1+\lambda) \sigma_{0}+2(1-\lambda) \sigma_{0} \cos 2 \theta-Y\right] \text {. }
$$

When $\lambda=1$, equation (17) can be transferred into radial contact stress in the elastoplastic zone with uniform pressure as given in equation (18), which is the same with the result given by Park [5]:

$$
p_{y_{2}}=\frac{2 \sigma_{0}-Y}{1+\xi} \text {. }
$$

\subsection{Solution of Stress and Deformation of Plastic Zone}

2.4.1. Stress and Radius of Plastic Zone. The stress of the plastic zone should satisfy the yield criterion and equilibrium equation under the postpeak state. By combining equations (2) and (5) with the stress boundary condition $\sigma_{r p}=p_{\text {in }}$ in the position of $r=r_{0}$, the expression of stress can be deduced as follows:. 


$$
\left\{\begin{array}{l}
\sigma_{r p}=H_{1}\left(\frac{r}{r_{0}}\right)^{\xi_{r}-1}+H_{2} \\
\sigma_{\theta p}=\xi_{r} H_{1}\left(\frac{r}{r_{0}}\right)^{\xi_{r}-1}
\end{array}\right.
$$

where the subscript notation $p$ represents the plastic zone, $H_{1}=p_{\text {in }}-\left(Y_{r} / 1-\xi_{r}\right)$, and $H_{2}=\left(Y_{r} / 1-\xi_{r}\right)$.

From equations (14a) and (14b), it shows that the radius of the plastic zone should be determined first to obtain the closed analytical solution of the stress in the surrounding rock. According to the boundary conditions at the elastoplastic interface, $r=r_{j}$, and $\left(\sigma_{r p}\right)_{r=r j}=p_{y_{1}}$, the radius of the plastic zone is proposed by combining equations (17) and (19):

$$
r_{j_{1}}=r_{0}\left[\frac{(1+\lambda) \sigma_{0}+2(1-\lambda) \sigma_{0} \cos 2 \theta-Y}{(1+\xi) H_{1}}-\frac{H_{2}}{H_{1}}\right]^{\left(1 / \xi_{r}-1\right)} \text {. }
$$

2.4.2. Displacement of Plastic Zone. It is assumed that the circumferential strain and radial strain in the plastic zone are both composed of elastic and plastic strain, and the total strain is

$$
\left\{\begin{array}{l}
\varepsilon_{\mathrm{rp}}=\varepsilon_{r}^{e}+\varepsilon_{r}^{p} \\
\varepsilon_{\theta p}=\varepsilon_{\theta}^{e}+\varepsilon_{\theta}^{p}
\end{array}\right.
$$

where $\varepsilon_{\mathrm{rp}}$ and $\varepsilon_{\theta p}$ are the total radial and circumferential strain, respectively; $\varepsilon_{r}^{p}$ and $\varepsilon_{\theta}^{p}$ are the radial and circumferential plastic strain, respectively; and $\varepsilon_{r}^{e}$ and $\varepsilon_{\theta}^{e}$ are the radial and circumferential elastic strain, respectively.

In any cases, the plastic deformation of rock should satisfy the flow rule, which is determined by the plastic potential function. Corresponding to the Mohr-Coulomb yield criterion, the following potential function is used:

$$
\phi=\sigma_{\theta}-\beta_{r} \sigma_{r}
$$

where $\beta_{r}=(1+\sin \psi) /(1-\sin \psi)$ and $\psi$ is the dilation angle of rock. If the dilation angle is not equal to the frictional angle, a nonassociated flow rule is used.

Based on plastic potential theory, the circumferential and radial plastic stresses in plastic zone are

$$
\left\{\begin{array}{l}
\varepsilon_{\theta}^{p}=\lambda_{p} \frac{\partial \phi}{\partial \sigma_{\theta p}} \\
\varepsilon_{r}^{p}=\lambda_{p} \frac{\partial \phi}{\partial \sigma_{\mathrm{rp}}}
\end{array}\right.
$$

where $\lambda_{p}$ is the parameter related to plastic strain.

Substituting equation (22) into equation (23), the plastic strain in the plastic zone should satisfy the following relationship:

$$
\varepsilon_{r}^{p}+\beta_{r} \varepsilon_{\theta}^{p}=0
$$

And substituting equations (21) and (24) into equation (6), the differential equation of radial displacement of the plastic zone is

$$
\frac{\mathrm{d} u_{r p}}{\mathrm{~d} r}+\beta_{r} \frac{u_{r p}}{r}=g(r),
$$

where $g(r)=\varepsilon_{r}^{e}+\beta_{r} \varepsilon_{\theta}^{e}$.

According to radial displacement continuous condition $u_{r p}=u_{r_{j}}$ in the position of $r=r_{j}$, the radial displacement of the plastic zone is obtained by solving equation (25):

$$
u_{r p}=\frac{1}{r^{\beta_{r}}} \int_{r_{j}}^{r} g(r) r^{\beta_{r}} \mathrm{~d} r+u_{r_{j}}\left(\frac{r_{j}}{r}\right)^{\beta_{r}} \text {. }
$$

According to equation (26), it may be seen that the displacement of the plastic zone is closely related to the elastic stain $g(r)$. By taking into account Young's modulus attenuation along the radial direction, the elastic strain at a specific position in the plastic zone can be expressed as follows:

$$
\left\{\begin{array}{l}
\varepsilon_{\theta}^{e}=\frac{1+v_{r}}{E(r)}\left[\left(1-v_{r}\right)\left(\sigma_{\theta p}-\sigma_{0}\right)-v_{r}\left(\sigma_{r p}-\sigma_{0}\right)\right], \\
\varepsilon_{r}^{e}=\frac{1+v_{r}}{E(r)}\left[\left(1-v_{r}\right)\left(\sigma_{r p}-\sigma_{0}\right)-v_{r}\left(\sigma_{\theta p}-\sigma_{0}\right)\right] .
\end{array}\right.
$$

Substituting equation (27) into equation $g(r)=\varepsilon_{r}^{e}+\beta_{r} \varepsilon_{\theta}^{e}$, the expression of $g(r)$ is

$$
\begin{aligned}
g(r)= & \frac{1+\nu_{r}}{E(r)}\left[\left(1-\nu_{r}-v_{r} \beta_{r}\right) \sigma_{r p}+\left(\beta_{r}-\nu_{r} \beta_{r}-v_{r}\right) \sigma_{\theta p}\right. \\
& \left.+\left(2 \nu_{r}-1\right)\left(1+\beta_{r}\right) \sigma_{0}\right] .
\end{aligned}
$$

Substituting equation (19) into (28), equation $g(r)$ with M-C criterion can be obtained:

$$
g(r)=\frac{1+v_{r}}{E(r)}\left[\delta_{1}\left(\frac{r}{r_{0}}\right)^{\xi_{r}-1}+\delta_{2}\right]
$$

where $\delta_{1}=\left[\left(1-v_{r}-\nu_{r} \beta_{r}\right)+\xi_{r}\left(\beta_{r}-v_{r} \beta_{r}-\nu_{r}\right)\right] H_{1} \quad$ and $\delta_{2}=\left(1-2 \nu_{r}\right)\left(1+\beta_{r}\right)\left(H_{2}-\sigma_{0}\right)$.

From equations (26) and (29), it is known that the deformation of surrounding rock is closely related with Young's modulus in the plastic zone. In order to analyze the influence of different attenuation functions of Young's modulus on the rock deformation, based on the RDM in equation (3), three expressions for Young's modulus attenuation are proposed:

(i) Case 1: when $\alpha=0$ and $E=E(r)=E_{r}$, Young's modulus of rock in the plastic zone is the initial one, which means that the effect of Young's modulus attenuation on rock deformation is ignored

(ii) Case 2: when $\alpha=0$ and $E \neq E(r)=E_{r}$, Young's modulus of rock in the plastic zone is the residual one, which is a constant 
(iii) Case 3: when $\alpha>0$ and $E(r)=E_{r}\left(r / r_{0}\right)^{\alpha}$, Young's modulus of rock in the plastic zone decreases, as defined in RDM

For Cases 1 and 2, substituting equations (29) into (26), the displacement of the plastic zone without considering the $\mathrm{RDM}$ is

$$
\begin{aligned}
u_{r p}^{\text {case } 1,2}= & \frac{1}{2 G_{r} r^{\beta_{r}}}\left[\delta_{1} f_{1}(r)+\delta_{2} f_{2}(r)-\delta_{1} f_{1}\left(r_{j}\right)\right. \\
& \left.-\delta_{2} f_{2}\left(r_{j}\right)+2 G_{r} u_{r j} r_{j}^{\beta_{r}}\right],
\end{aligned}
$$

where $G_{r}=E_{r} /\left[2\left(1+v_{r}\right)\right], f_{1}(r)=\left(1 / r_{0}^{\xi_{r}-1}\right)\left(r^{\beta_{r}+\xi_{r}} / \xi_{r}+\beta_{r}\right)$, $f_{1}\left(r_{j}\right)=\left(1 / r_{0}^{\xi_{r}-1}\right)\left(r_{j}^{\beta_{r}+\xi_{r}} / \xi_{r}+\beta_{r}\right), \quad f_{2}(r)=\left(r^{\beta_{r}+1} / 1+\beta_{r}\right)$, and $f_{2}\left(r_{j}\right)=\left(r_{j}^{\beta_{r}+1} / 1+\beta_{r}\right)$.

Similarly, with Case 3, substituting equations (3) and (29) into (26), the displacement of the plastic zone considering the RDM is

$$
u_{r p}^{\text {case } 3}=\frac{1}{2 G_{r} r^{\beta_{r}}}\left[c_{3}\left(r^{c_{1}}-r_{j}^{c_{1}}\right)+c_{4}\left(r^{c_{2}}-r_{j}^{c_{2}}\right)+2 G_{r} u_{r_{j}} r_{j}^{\beta_{r}}\right],
$$

where $\quad c_{1}=\beta_{r}+\xi_{r}-\alpha, \quad c_{2}=\beta_{r}-\alpha+1, \quad c_{3}=$ $\left(\delta_{1} / r_{0}^{\xi_{r}-\alpha-1}\left(\beta_{r}+\xi_{r}-\alpha\right)\right)$, and $c_{4}=\left(\delta_{2} / r_{0}^{-\alpha}\left(\beta_{r}-\alpha+1\right)\right)$.

\section{Analytical Results}

3.1. Model Validation and Comparison. Comparing with the closed-form solutions in the literature, the presented work takes lateral pressure coefficient and Young's modulus attenuation into consideration. When $\lambda=1, \alpha=0$, and $v=v_{r}$, the model provides solution for the condition of uniform stress and constant Young's modulus, which has been studied by Park [5]. To verify the accuracy of the proposed model, results of the proposed model and Park's solution were compared, as shown in Figure 3. The geometric and physical parameters are listed in Table 1.

As shown in Figure 3, when $\lambda=1, \alpha=0$, and $v=v_{r}=0.2$, the proposed model in the present study provides the same result as that of Park's research. Therefore, the result of Park's research is a special case of present work.

\subsection{Effect of Lateral Pressure Coefficient on the Distribution of} Plastic Zone. The elastoplastic radial contact stress and the radius of the plastic zone under nonuniform pressure can be obtained by equations (17) and (19). The distribution of the plastic zone is shown in Figure 4, which shows that the lateral pressure coefficient has important influence on the distribution of the plastic zone. When $0<\lambda<1$, the ranges of the plastic zone in side walls are larger than those in the roof and floor; when $\lambda>1$, the results are on the contrary. Besides, when the lateral pressure coefficient increases, the ranges of the plastic zone in side walls shrink, while those in roof and floor increase.

3.3. Effect of Lateral Pressure Coefficient on the Surface Displacement of Surrounding Rock. The radial displacement on the surface of opening under nonuniform pressure was obtained by equations (30) and (31), as shown in Figure 5. It shows that the lateral pressure coefficient has remarkable effects on the surface displacement. With the increase of lateral pressure coefficient, the surface displacement decreases at the sides of opening and increases around the roof. For example, when $\beta_{r}=2$ and $\lambda$ increases gradually from 0.8 to $1.2 \sim 1.5$, the displacement at roof increases by $1.07 \mathrm{~mm}$ to $1.37 \mathrm{~mm}$, which is 202 to 258 percent; while the displacement at side wall decreases by approximately $0.39 \mathrm{~mm}$ to $0.67 \mathrm{~mm}$, which is 30 to 52 percent. Meanwhile, when $0<\lambda<1$, the surface displacement at side wall is larger than at roof and floor; however, when $\lambda>1$, the results are on the contrary.

From Figure 5, it is also known that the surface displacement increases greatly with the increase of the dilation coefficient. For example, when $\lambda=0.8$ and $\beta_{r}$ changes from 1 to $1.5 \sim 2$, the surface displacement at roof, spandrel $\left(60^{\circ}\right)$ and side wall increase about 0.06 to $0.13 \mathrm{~mm}, 0.11$ to $0.24 \mathrm{~mm}$, and 0.25 to $0.63 \mathrm{~mm}$, respectively, which vary by 15 to 32.5 , 22.91 to 50 , and 37.31 to 94.03 percent, respectively. We may conclude that the dilation coefficient also has great influence on surface displacement of surrounding rock.

3.4. Effect of the Buried Depth on Maximum Surface Displacement of Surrounding Rock. The maximum surface displacement of surrounding rock is given in Figure 6. It may be seen that the surface displacement increases with the burial depth by exponential law. For example, when $\lambda=1.2$ and $\sigma_{0}$ varies from 1 to $1.2 \sim 1.8 \mathrm{MPa}$, the displacement increases from 3.3 to $20.7 \mathrm{~mm}$, which means a great influence of the buried depth on the deformation of surrounding rock. It is important to note that the location of the maximum displacement is also different with different lateral pressure coefficients. When $0<\lambda<1$, the location of the maximum surface displacement occurs in two sides $\left(0^{\circ}\right)$; otherwise, when $\lambda>1$, the maximum displacement distributes in the roof and floor $\left(90^{\circ}\right.$ or $\left.270^{\circ}\right)$.

3.5. Effect of Lateral Pressure Coefficient on Response Curve between Surrounding Rock and Support. According to the analytical solution, the response curve between the surrounding rock and support can be deduced (Figure 7 ). It can be seen that the lateral pressure coefficient influences the response curve in two aspects. First, that response curve varies at different sites under specific lateral pressure coefficient. Second, the location of the maximum value of response curve transfers from side $\left(0^{\circ}\right)$ to roof $\left(90^{\circ}\right)$ with the increasing of lateral pressure coefficient, which is in accordance with the deformation of surrounding rock.

As shown by the above analysis, the influence of lateral pressure coefficient should be taken into full consideration for the design of the primary support under nonuniform pressure, and the reinforced support should be carried out in the key parts to prevent rock instability.

Table 2 illustrates the critical support resistance of each position when the surrounding rock begins to show the plastic state. If $p_{\text {in }}>p_{y c}$, it means that the part of surrounding rock is in the elastic state, whose response curve could be 


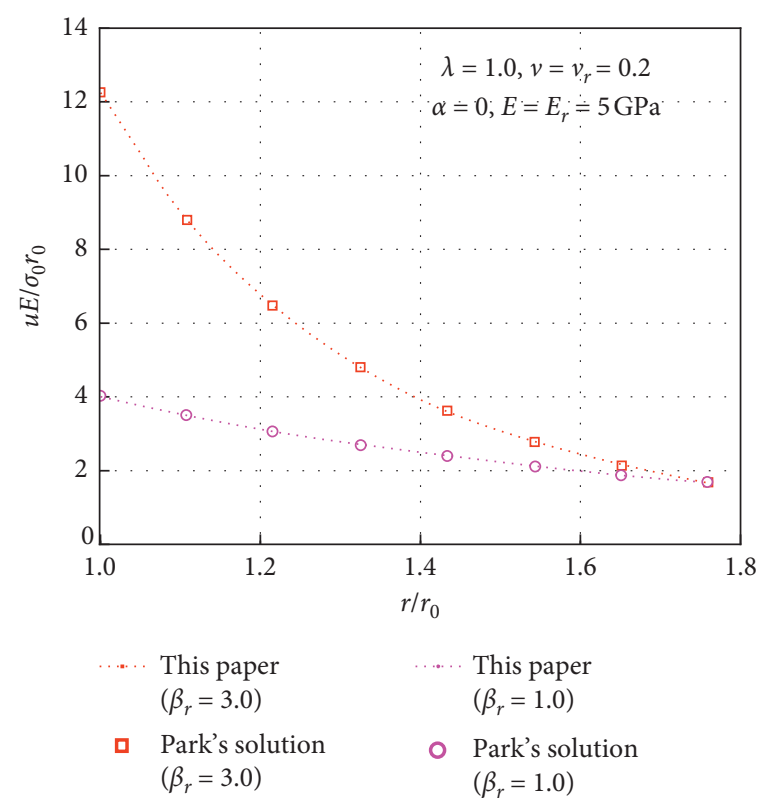

(a)

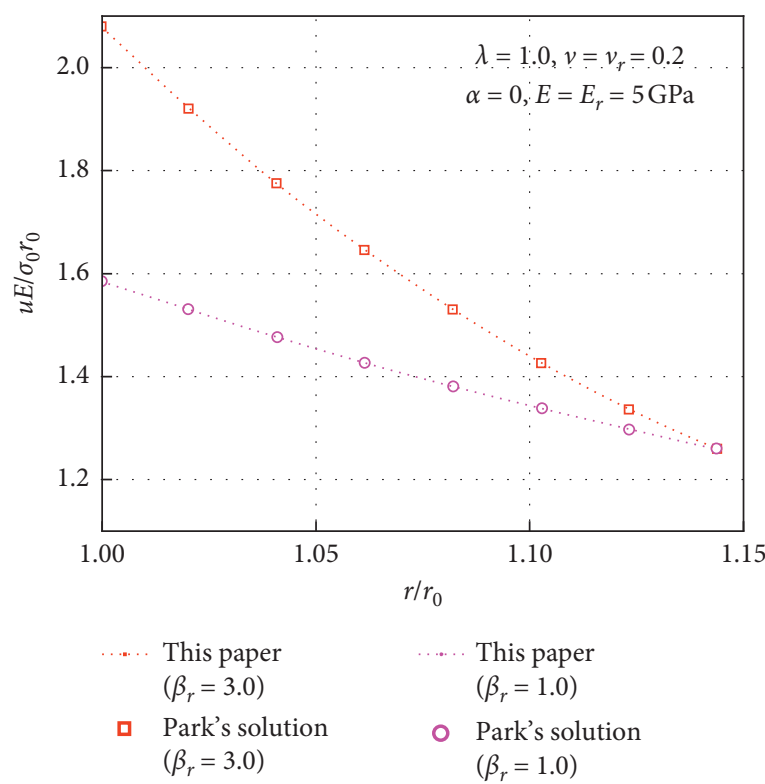

(b)

FIGURE 3: Comparisons between displacement of plastic zone in this paper and Park's solution. (a) The solution with soft rock parameters. (b) The solution with hard rock parameters.

TABLE 1: Geometrical and physical parameters of a circular opening [5].

\begin{tabular}{lcc}
\hline Parameters & Hard rock & Soft rock \\
\hline Radius of opening, $r_{0}(\mathrm{~m})$ & 1 & 1 \\
Initial stress, $\sigma_{0}(\mathrm{MPa})$ & 1 & 1 \\
Internal pressure, $p_{\text {in }}(\mathrm{MPa})$ & 0 & 0 \\
Young's modulus, $E(\mathrm{MPa})$ & 50,000 & 5000 \\
Poisson's ratio, $v$ & 0.2 & 0.2 \\
Shear modulus, $G(\mathrm{MPa})$ & 20,833 & 2083 \\
$\beta_{r}\left({ }^{\circ}\right)$ & 3 & 3 \\
$c(\mathrm{MPa})$ & 0.173 & 0.276 \\
$\varphi\left({ }^{\circ}\right)$ & 55 & 35 \\
$c_{r}(\mathrm{MPa})$ & 0.061 & 0.055 \\
$\varphi_{r}\left({ }^{\circ}\right)$ & 52 & 30 \\
\hline
\end{tabular}

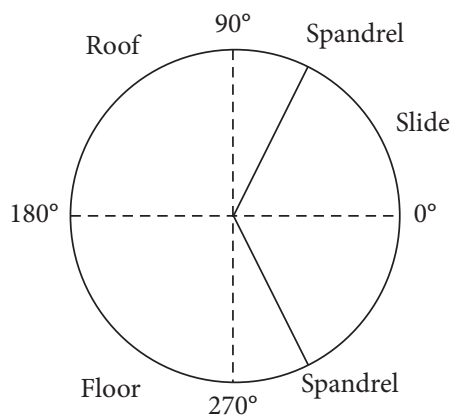

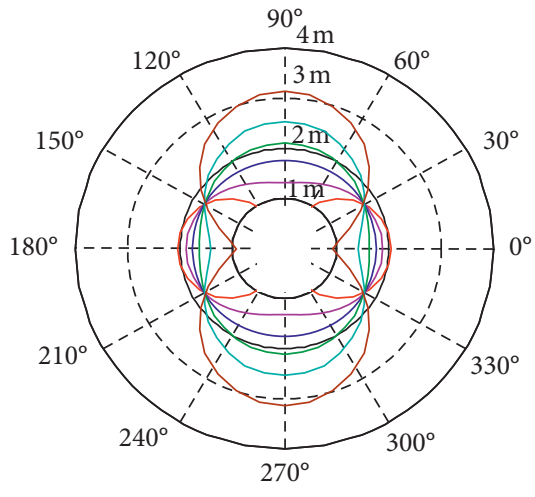

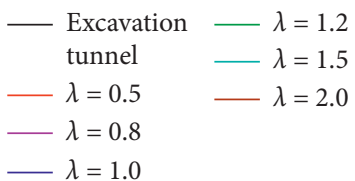

(b)

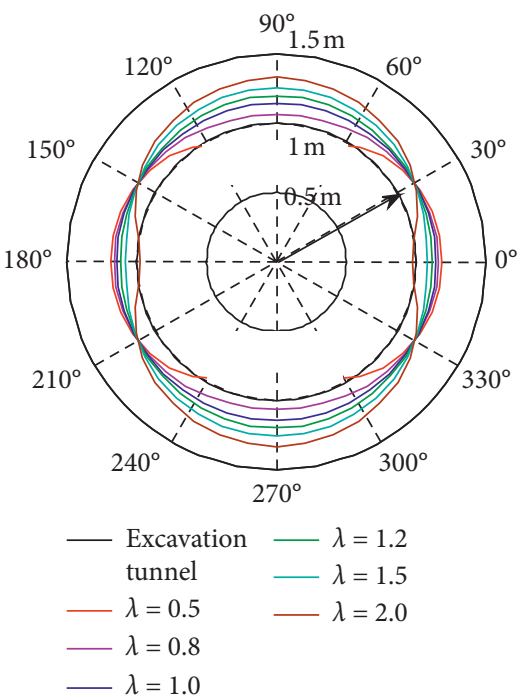

(c)

FIgURE 4: Effect of lateral pressure coefficient on the distribution of the plastic zone. (a) The polar coordinate system for the postprocessing of the results. (b) The result with soft rock parameters. (c) The result with hard rock parameters. 


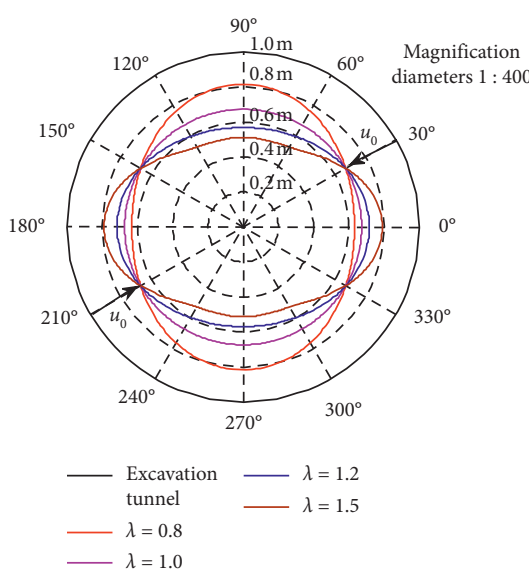

(a)

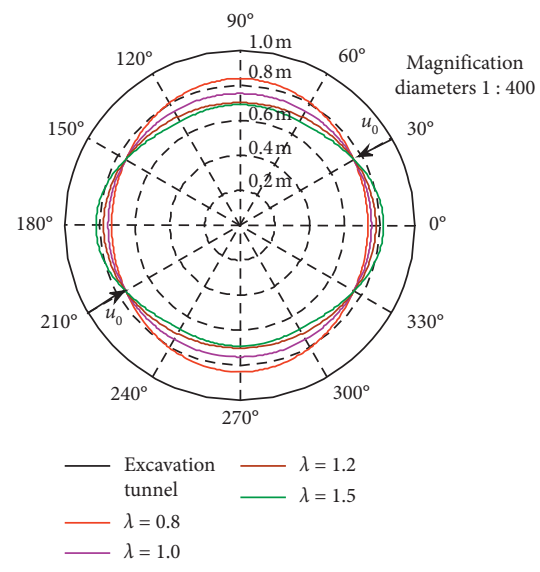

(b)

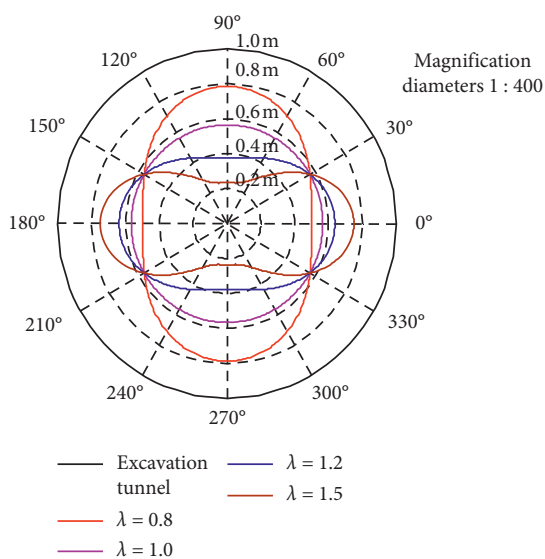

(c)

Figure 5: Effect of lateral pressure coefficient on the surface displacement of surrounding rock. Parameter values: $v=v_{r}=0.2, \alpha=0, E=E_{r}=5 \mathrm{GPa}$. (a) $\sigma_{0}=1 \mathrm{MPa}, \beta_{r}=1.5$. (b) $\sigma_{0}=1 \mathrm{MPa}, \beta_{r}=1.0$. (c) $\sigma_{0}=1 \mathrm{MPa}, \beta_{r}=2$. $u_{0}$ is the radial displacement at the surface of tunnel. Note. As the displacement at the surface of surrounding rock is small, the result is scaled up by $1: 400$ to give a more intuitive illustration.

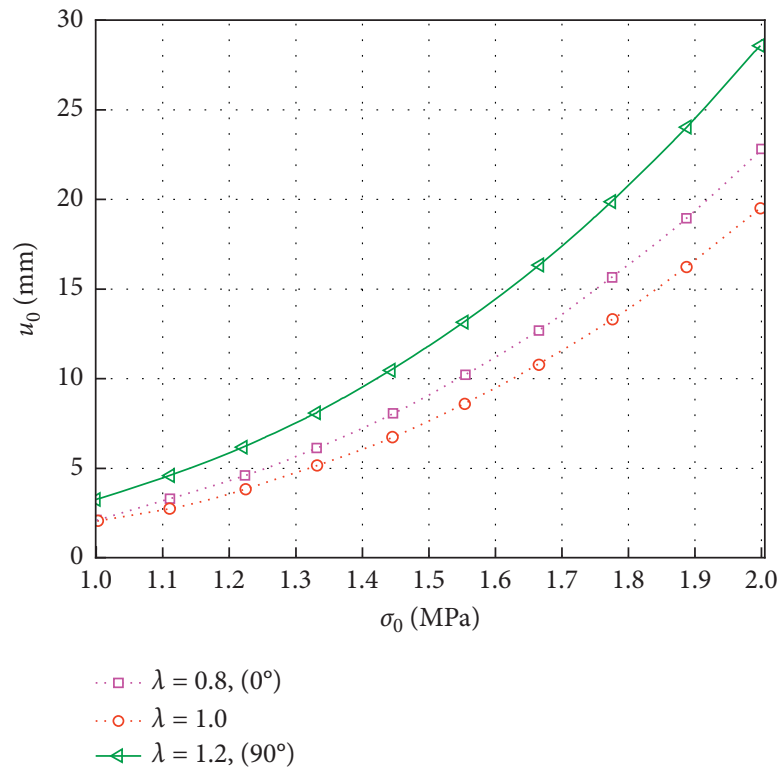

Figure 6: Effect of the maximum surface displacement of surrounding rock with burial depth. Parameter values: $v=v_{r}=0.2$, $\alpha=0, E=E_{r}=5 \mathrm{GPa}$, and $\beta_{r}=3.0$.

obtained by equation (15); on the contrary, if $p_{\text {in }}<p_{y c}$, it means the part of surrounding rock is in the plastic state, whose response curve could be obtained by equation (30) or (31).

3.6. Effect of Young's Modulus Attenuation on Radial Displacement of Plastic Zone. The change law of radial displacement of the plastic zone with the increasing radius is shown in Figure 8 in different cases of Young's modulus attenuation. It is known that Young's modulus attenuation has great influence on radial displacement of the plastic zone when using RDM. For example, at side position $\left(0^{\circ}\right)$, comparing Case 2 and Case 3 with Case 1, the surface displacement of plastic zone $\left(u E / \sigma_{0} r_{0}\right)$ increases 9.91 and 2.77 , respectively, which is increased by 103 and 29 percent. Therefore, it indicates that the damage of surrounding rock in Case 2 is largest, while the one in Case 1 is smallest.

3.7. Effect of Young's Modulus Attenuation on the Response Curve between Surrounding Rock and Support. The response curves between surrounding rock and support are shown in Figure 9 in different cases of Young's modulus attenuation. It shows that when Young's modulus attenuation is ignored (Case 1), the deformation of the surrounding rock and support force will be underestimated; however, when a residual value of Young's modulus is assumed in the plastic 


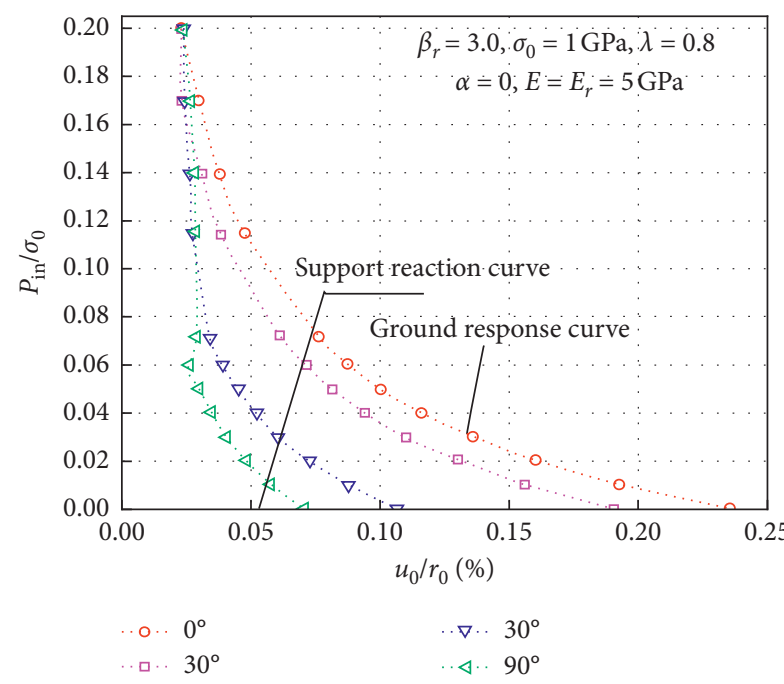

(a)

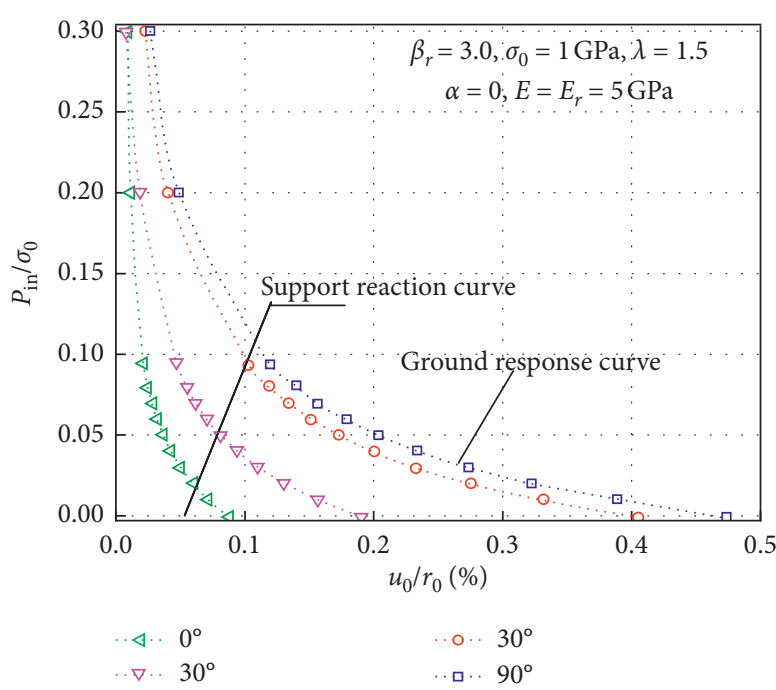

(b)

FIGURE 7: Changes of the response curve between rock wall and support frame with different lateral pressure coefficients. Parameter values: soft rock $v=v_{r}=0.2, \beta_{r}=3.0, \alpha=0$, and $E=E_{r}=5 \mathrm{GPa}$. The lateral pressure coefficient of (a) $\lambda=0.8$ and (b) $\lambda=1.5$.

TABLE 2: The changes of critical support resistance $\left(p_{y c}\right)$ when the surrounding rock changes from elastic to plastic state.

\begin{tabular}{lcccc}
\hline Lateral pressure coefficient & $0^{\circ}$ side $(\mathrm{MPa})$ & $30^{\circ}$ spandrel $(\mathrm{MPa})$ & $60^{\circ}$ spandrel $(\mathrm{MPa})$ & $90^{\circ}$ roof $(\mathrm{MPa})$ \\
\hline$\lambda=0.8$ & 0.243 & 0.200 & 0.115 & 0.072 \\
$\lambda=1.5$ & 0.094 & 0.200 & 0.414 & 0.520
\end{tabular}
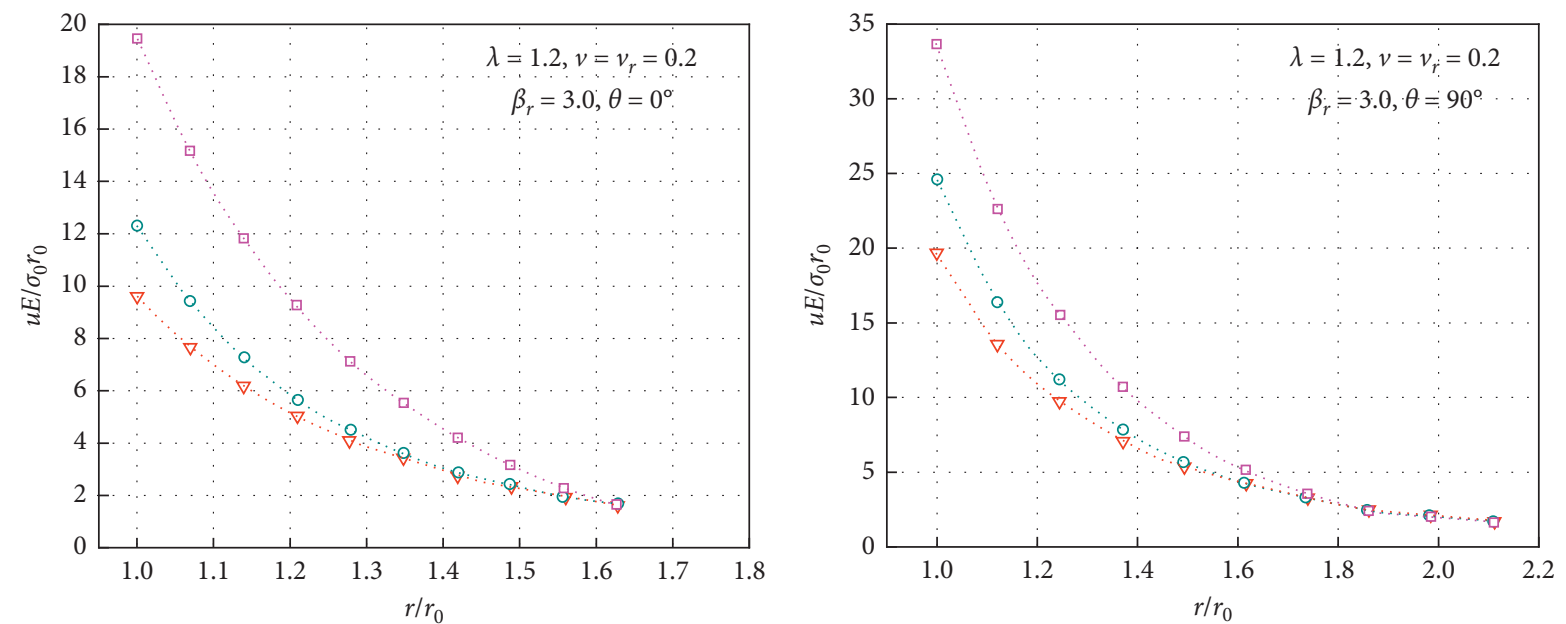

$\nabla$. Case1 $\left(\alpha=0, E=E_{r}=5 \mathrm{GPa}\right)$
‥ Case2 $\left(\alpha=0, E=E_{r}=1 \mathrm{GPa}\right)$
. Case3 $(\alpha>0, \mathrm{RDM}$ model $)$

(a)

$$
\begin{aligned}
& . \nabla \cdot \text { Case } 1\left(\alpha=0, E=E_{r}=5 \mathrm{GPa}\right) \\
& . \square \cdot \text { Case } 2\left(\alpha=0, E=E_{r}=1 \mathrm{GPa}\right) \\
& . \circ \cdot \text { Case } 3(\alpha>0, \mathrm{RDM} \text { model })
\end{aligned}
$$

(b)

Figure 8: Effect of Young's modulus attenuation model on the surface displacement of surrounding rock. Soft rock, $\sigma_{0}=1 \mathrm{MPa}, \lambda=1.2$, $v=v_{r}=0.2$, and $\beta_{r}=3$. (a) The curve at side position $\left(0^{\circ}\right)$. (b) The curve at the roof $\left(90^{\circ}\right)$. 


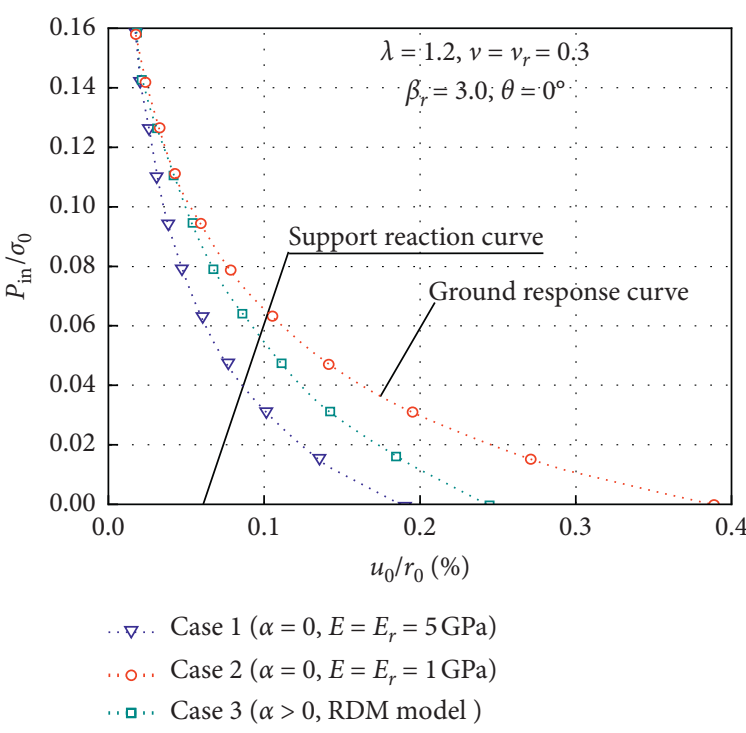

(a)

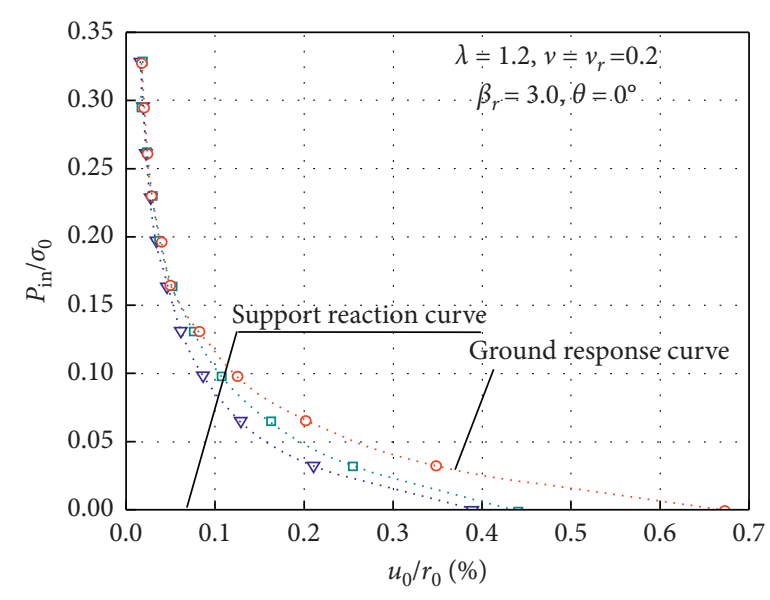

$$
\begin{aligned}
& \therefore \nabla . \text { Case } 1\left(\alpha=0, E=E_{r}=5 \mathrm{GPa}\right) \\
& \therefore \circ . \text { Case } 2\left(\alpha=0, E=E_{r}=1 \mathrm{GPa}\right) \\
& \therefore \square . \text { Case } 3(\alpha>0, \mathrm{RDM} \text { model })
\end{aligned}
$$

(b)

Figure 9: Effect of Young's modulus attenuation on the response curve between surrounding rock and support. Soft rock, $\lambda=1.2$,

\begin{tabular}{|c|c|c|c|c|c|}
\hline Site & $\begin{array}{c}\text { Buried } \\
\text { depth }(\mathrm{m})\end{array}$ & $\begin{array}{c}\text { In situ stress } \\
\text { state }\end{array}$ & $\begin{array}{c}\text { Deformation } \\
\text { features }\end{array}$ & Support schemes & $\begin{array}{c}\text { Support } \\
\text { effects }\end{array}$ \\
\hline $\begin{array}{l}\text { No. } 1 \text { coal } \\
\text { mine }[13]\end{array}$ & 930 & $\lambda=1.2$ & $\begin{array}{l}\text { Roof (floor) } \\
\quad>\text { side }\end{array}$ & $\begin{array}{c}\text { Deep hole grouting + shallow hole grouting + whole section } \\
\text { high-strength bolt (rope) support }\end{array}$ & Stable \\
\hline $\begin{array}{l}\text { No. } 2 \text { coal } \\
\text { mine }[12]\end{array}$ & 535 & $\lambda=0.3$. & $\begin{array}{l}\text { Roof (floor) } \\
\quad<\text { side }\end{array}$ & Shallow hole grouting + high-strength bolt (rope) support & Stable \\
\hline $\begin{array}{l}\text { No. } 3 \text { coal } \\
\text { mine }[16]\end{array}$ & 640 & $\lambda=1.5$ & $\begin{array}{l}\text { Roof (floor) } \\
\quad>\text { side }\end{array}$ & Grouting + cable anchor + flexible truss yield support & Stable \\
\hline $\begin{array}{l}\text { No. } 4 \text { coal } \\
\text { mine [38] }\end{array}$ & 860 & $\lambda=1.36$ & $\begin{array}{l}\text { Roof (floor) } \\
>\text { side }\end{array}$ & Cable anchor + concrete lining + steel pipe arch support & Stable \\
\hline
\end{tabular}
$v=v_{r}=0.2$, and $\beta_{r}=3$. (a) The curve at side position $\left(0^{\circ}\right)$. (b) The curve at roof position $\left(90^{\circ}\right)$.

TABLE 3: Summary of cases on fracture and support scheme of opening under nonuniform pressure.

zone (Case 2), the deformation of the surrounding rock and support force will be overestimated. The RDM (Case 3) seems to give more reasonable results and is recommended for design of support parameters and stability analysis of surrounding rock in the circular tunnel.

\section{Support Design for Opening under Nonuniform Pressure}

According to the above analysis, it is known that the lateral pressure coefficient is the main reason for nonuniform distribution of the plastic zone and deformation of surrounding rock. When $0<\lambda<1$, the range of the plastic zone and deformation presents larger at side than roof positions, while when $\lambda>1$, the result is on the contrary. The rule was also verified well in many engineering practices in deep openings [12-16], as shown in Table 3.

Many support techniques of deep opening under nonuniform pressure were put forward, such as bolt-grouting support, bolt-grouting and flexible arch combined support, and bolt-mesh-cable and bolt-grouting combined support.
The principles of support design can be concluded in three aspects as follows:

(1) Allocate the key parts (where the surrounding rock fails easily) and provide reinforced support in these areas. Due to the nonuniform deformation around the opening induced by the nonuniform initial pressure, the deformation of the support structure is inhomogeneous, which may cause buckling failure of the support. Therefore, reinforced support around the key parts is needed to control the nonuniform deformation of surrounding rock and make the support structure bear uniform pressure [38]. Specifically speaking, when $0<\lambda<1$, the key locations are around the side wall, and when $\lambda<1$, the key locations are around the roof and floor.

(2) Improve the self-bearing capacity of surrounding rock by grouting reinforcement. The grouting reinforcement can increase the strength of rock mass and make it response elastically. Based on the results of present research, the distribution of grouting boreholes can be optimized to account for the nonuniform plastic zone extent. 


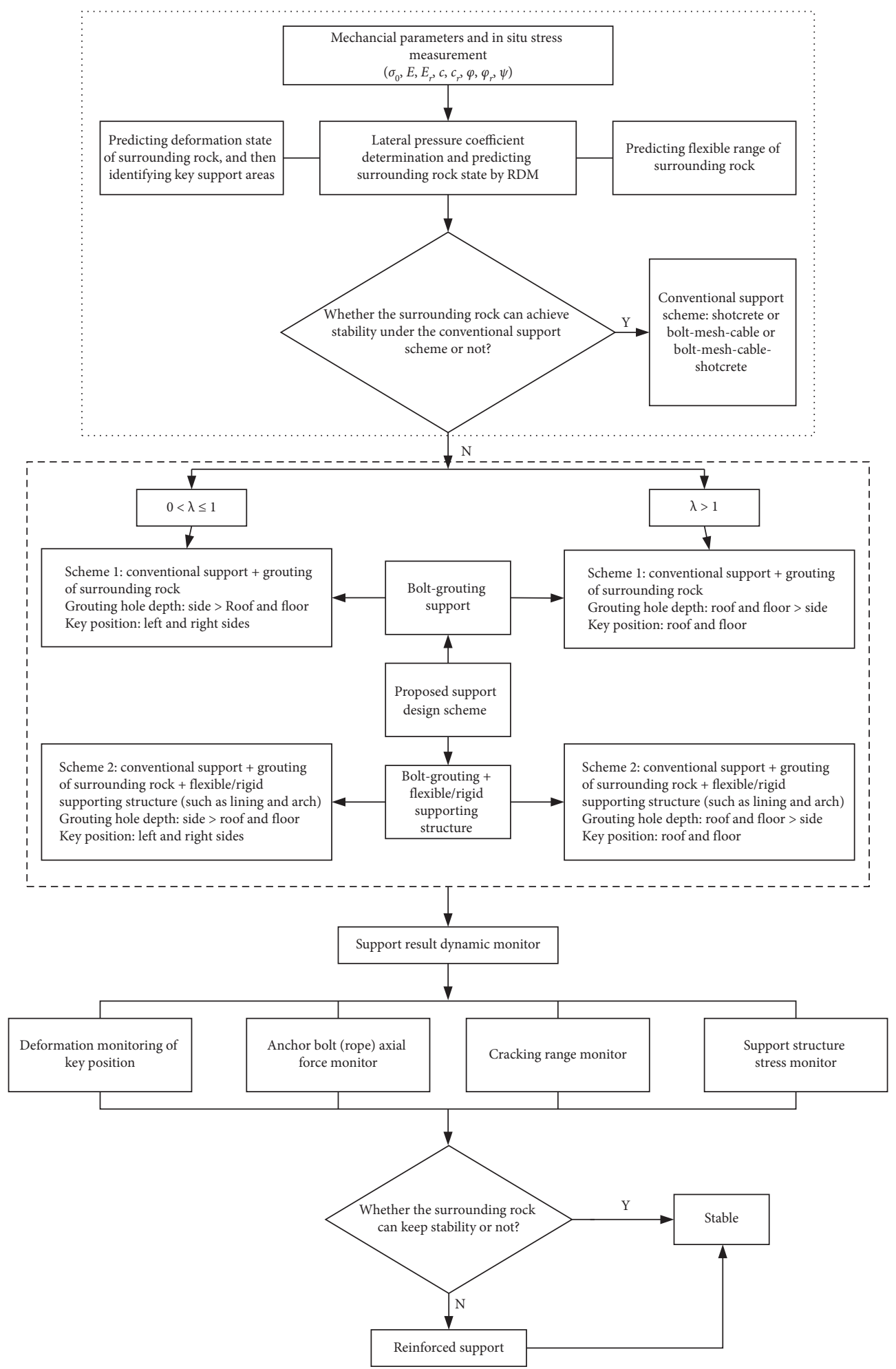

FIGURE 10: Optimization flow of support scheme of deep circular opening under nonuniform pressure.

(3) Use flexible support structure if rigid support bears too heavy load, especially for the key parts.

Combining engineering practices and theoretical analysis results, an optimization method for support design was proposed for deep circular opening under nonuniform pressure. The specific optimization flow is shown in Figure 10.

\section{Conclusions}

The mechanical model of a circular opening with nonuniform pressure was proposed, which takes into account the nonassociated flaw rule and Young's modules attenuation. The closed-form solutions of stress, deformation, and radius of the plastic zone of surrounding rock were obtained. The 
influences of some factors including lateral pressure coefficient, dilation coefficient, buried depth, and Young's modules attenuation on the state of surrounding rock were analyzed. The following conclusions can be drawn:

(1) An analytical solution of a circular opening with nonuniform pressure was obtained. Compared with the results under uniform pressure in the literature, the proposed analytical solution is verified.

(2) The lateral pressure coefficient has remarkable influence on the distribution of the plastic zone. When $0<\lambda<1$, the ranges of the plastic zone around side walls are larger than those of the roof and floor; when $\lambda>1$, the results are on the contrary. Besides, with the increasing of lateral pressure coefficient, the range of the plastic zone in side walls shrinks gradually, while that in the roof and floor increases.

(3) The lateral pressure coefficient has an impact on surrounding rock deformation and response curve of the support. With the consideration on the effect of lateral pressure coefficient, both the deformation and response curve show nonuniform characteristic around the tunnel.

(4) The surface displacement of surrounding rock increases with dilation coefficient and buried depth. Therefore, their effect on deformation of surrounding rock should be taken a full account on support design.

(5) Young's modulus attenuation has important influence on radial displacement of plastic zone. When the attenuation effect is ignored, it will cause underestimation for the deformation of surrounding rock. The RDM can be more effective on the design of support parameters and stability analysis of surrounding rock in deep circular opening.

\section{Data Availability}

The data used to support the findings of this study are available from the corresponding author upon request.

\section{Conflicts of Interest}

The authors declare that there are no conflicts of interest regarding the publication of this paper.

\section{Acknowledgments}

The authors acknowledge financial support by the National Natural Science Foundation of China (nos. 51974295 and 51874278), the Natural Science Foundation of Jiangsu Province of China (no. BK20181357), the Foundation Research Project of Jiangsu Province (no. BK20181357), the "Six Talent Peaks" Project of Jiangsu Province (no. JNHB087), the Talent Support Project of Jiangsu Association for Science and Technology (no. 2019-134), and the Independent Research Project of State Key Laboratory of Coal Resources and Safe Mining (no. SKLCRSM2020X04).

\section{References}

[1] A. L. Florence and L. E. Schwer, "Axisymmetric compression of a Mohr-Coulomb medium around a circular hole," International Journal for Numerical \& Analytical Methods in Geomechanics, vol. 2, no. 4, pp. 367-379, 2010.

[2] C. Carranza-Torres and C. Fairhurst, "Application of the Convergence-Confinement method of tunnel design to rock masses that satisfy the Hoek-Brown failure criterion," Tunnelling and Underground Space Technology, vol. 15, no. 2, pp. 187-213, 2000.

[3] S. K. Sharan, "Exact and approximate solutions for displacements around circular openings in elastic-brittle-plastic Hoek-Brown rock," International Journal of Rock Mechanics and Mining Sciences, vol. 42, no. 4, pp. 542-549, 2005.

[4] S. K. Sharan, "Analytical solutions for stresses and displacements around a circular opening in a generalized HoekBrown rock," International Journal of Rock Mechanics and Mining Sciences, vol. 45, no. 1, pp. 78-85, 2008.

[5] K.-H. Park and Y.-J. Kim, "Analytical solution for a circular opening in an elastic-brittle-plastic rock," International Journal of Rock Mechanics and Mining Ences, vol. 43, no. 4, pp. 616-622, 2006.

[6] K.-H. Park, B. Tontavanich, and J.-G. Lee, "A simple procedure for ground response curve of circular tunnel in elasticstrain softening rock masses," Tunnelling and Underground Space Technology, vol. 23, no. 2, pp. 151-159, 2008.

[7] Y.-K. Lee and S. Pietruszczak, "A new numerical procedure for elasto-plastic analysis of a circular opening excavated in a strain-softening rock mass," Tunnelling and Underground Space Technology, vol. 23, no. 5, pp. 588-599, 2008.

[8] S. Wang, X. Yin, H. Tang, and X. Ge, "A new approach for analyzing circular tunnel in strain-softening rock masses," International Journal of Rock Mechanics and Mining Sciences, vol. 47, no. 1, pp. 170-178, 2010.

[9] R. C. F. Tonon, "Closed-form solutions for a circular tunnel in elastic-brittle-plastic ground with the original and generalized Hoek-Brown failure criteria," Rock Mechanics \& Rock Engineering, vol. 44, no. 2, pp. 169-178, 2011.

[10] Q. Zhang, B. S. Jiang, X. S. Wu, H. Q. Zhang, and L. J. Han, "Elasto-plastic coupling analysis of circular openings in elasto-brittle-plastic rock mass," Theoretical and Applied Fracture Mechanics, vol. 60, no. 1, pp. 60-67, 2012.

[11] J.-x. Han, S.-c. Li, S.-c. Li, and W.-m. Yang, "A procedure of strain-softening model for elasto-plastic analysis of a circular opening considering elasto-plastic coupling," Tunnelling and Underground Space Technology, vol. 37, pp. 128-134, 2013.

[12] W. Li, S. Li, C. Xuan et al., "Mechanism and control of failure of rock roadway support in highly stressed soft rock," Chinese Journal of Rock Mechanics and Engineering, vol. 34, no. 9, pp. 1836-1848, 2015.

[13] R. Yang, Y. Li, D. Guo, L. Yao, T. Yang, and T. Li, "Failure mechanism and control technology of water-immersed roadway in high-stress and soft rock in a deep mine," International Journal of Mining Science and Technology, vol. 27, no. 2, pp. 245-252, 2017.

[14] F. T. Wang, C. Zang, S. F. Wei et al., "Whole section anchor-grouting reinforcement technology and its application in underground roadways with loose and fractured surrounding rock," Tunnelling and Underground Space Technology, vol. 51, pp. 133-143, 2016.

[15] X. Yang, J. Pang, D. Liu et al., "Deformation mechanism of roadways in deep soft rock at Hegang Xing'an Coal Mine," 
International Journal of Mining Science and Technology, vol. 23, no. 2, pp. 307-312, 2013.

[16] P. Cao and H. Y. Li, "Instability mechanism and control measures of surrounding rock in deep tunnel under high lateral pressures," Chinese Journal of Geotechnical Engineering, vol. 38, pp. 2262-2270, 2016.

[17] Z.-H. Zhao, W.-M. Wang, and L. Wang, "Response models of weakly consolidated soft rock roadway under different interior pressures considering dilatancy effect," Journal of Central South University, vol. 20, no. 12, pp. 3736-3744, 2013.

[18] J.-f. Zou, S.-s. Li, X. Yuan, Y. Xu, H.-c. Dan, and L.-h. Zhao, "Theoretical solutions for a circular opening in an elasticbrittle-plastic rock mass incorporating the out-of-plane stress and seepage force," KSCE Journal of Civil Engineering, vol. 20, no. 2, pp. 687-701, 2016.

[19] Z. Zhang, C. a. Tang, Q. L. Yu, and D. Duan, "Numerical simulation on influence coefficient of lateral pressure on broken zone of circular aperture," Rock and Soil Mechanics, vol. 30, no. 2, pp. 413-418, 2009.

[20] E. T. Brown, J. W. Bray, and F. J. Santarelli, "Influence of stress-dependent elastic moduli on stresses and strains around axisymmetric boreholes," Rock Mechanics and Rock Engineering, vol. 22, no. 3, pp. 189-203, 1989.

[21] M. R. Asef and D. J. Reddish, "The impact of confining stress on the rock mass deformation modulus," Géotechnique, vol. 52, no. 4, pp. 235-241, 2002.

[22] M. Verman, B. Singh, M. N. Viladkar, and J. L. Jethwa, "Effect of tunnel depth on modulus of deformation of rock mass," Rock Mechanics and Rock Engineering, vol. 30, no. 3, pp. 121-127, 1997.

[23] C. Zhang, J. Zhao, Q. Zhang, and X. Hu, "A new closed-form solution for circular openings modeled by the Unified Strength Theory and radius-dependent Young's modulus," Computers and Geotechnics, vol. 42, pp. 118-128, 2012.

[24] R. T. Ewy and N. G. W. Cook, "Deformation and fracture around cylindrical openings in rock-I. Observations and analysis of deformations," International Journal of Rock Mechanics and Mining Sciences \& Geomechanics Abstracts, vol. 27, no. 5, pp. 387-407, 1990.

[25] P. A. Nawrocki and M. B. Dusseault, "Modelling of damaged zones around openings using radius-dependent Young's modulus," Rock Mechanics and Rock Engineering, vol. 28, no. 4, pp. 227-239, 1995.

[26] X. Chen, C. P. Tan, and C. M. Haberfield, "Solutions for the deformations and stability of elastoplastic hollow cylinders subjected to boundary pressures," International Journal for Numerical \& Analytical Methods in Geomechanics, vol. 23, no. 8, pp. 779-800, 2015.

[27] P. K. Kaiser, "A New Concept to Evaluate Tunnel Performance-Influence of Excavation Procedure," in Preceding of the 22nd US Symposium on Rock Mechanics, pp. 264-271, Cambridge, MA, USA, 1981.

[28] Z. F. Chu, Z. J. Wu, Q. S. Liu et al., "Analytical solutions for deep-buried lined tunnels considering longitudinal discontinuous excavation in rheological rock mass," Journal of Engineering Mechanics, vol. 146, no. 6, Article ID 04020047, 2020.

[29] Z. Chu, Z. Wu, B. Liu, and Q. Liu, "Coupled analytical solutions for deep-buried circular lined tunnels considering tunnel face advancement and soft rock rheology effects," Tunnelling and Underground Space Technology, vol. 94, Article ID 103111, 2019.

[30] F. Song, H. Wang, and M. Jiang, "Analytically-based simplified formulas for circular tunnels with two liners in viscoelastic rock under anisotropic initial stresses," Construction and Building Materials, vol. 175, pp. 746-767, 2018.

[31] F. Song, H. Wang, and M. Jiang, "Analytical solutions for lined circular tunnels in viscoelastic rock considering various interface conditions," Applied Mathematical Modelling, vol. 55, pp. 109-130, 2018.

[32] K. Wu and Z. S. S. Qin, "An analytical design method for ductile support structures in squeezing tunnels," Archives of Civil and Mechanical Engineering, vol. 20, no. 3, pp. 1-13, 2020.

[33] K. Wu, Z. Shao, S. Qin, N. Zhao, and H. Hu, "Analytical-based assessment of effect of highly deformable elements on tunnel lining within viscoelastic rocks," International Journal of Applied Mechanics, vol. 12, no. 3, Article ID 2050030, 2020.

[34] W. Kui, S. Z. Shan, S. Qin et al., "Determination of deformation mechanism and countermeasures in silty clay tunnel," Journal of Performance of Constructed, vol. 34, no. 1, 2020.

[35] K. Wu and Z. S. Shao, "Visco-elastic analysis on the effect of flexible layer on mechanical behavior of tunnels," International Journal of Applied Mechanics, vol. 11, no. 3, 2019.

[36] K. Wu and Z. S. Shao, "Study on the effect of flexible layer on support structures of tunnel excavated in viscoelastic rocks," Journal of Engineering Mechanics, vol. 145, no. 10, 2019.

[37] Z. L. Xu, Elasticity, Higher Education Press, Beijing, China, 2010.

[38] M. He, X. Lu, and H. Jing, "Characters of surrounding rockmass in deep engineering and its non-linear dynamicmechanical design concept," Chinese Journal of Rock Mechanics and Engineering, vol. 21, no. 8, pp. 1215-1224, 2002. 